\title{
GPNMB overexpression is associated with extensive bone metastasis and poor prognosis in renal cell carcinoma
}

\author{
JIAN-PO ZHAI, ZHEN-HUA LIU, HAI-DONG WANG, GUANG-LIN HUANG and LI-BO MAN \\ Department of Urology, Beijing Jishuitan Hospital, Beijing 102200, P.R. China
}

Received January 11, 2021; Accepted August 2, 2021

DOI: 10.3892/ol.2021.13154

\begin{abstract}
Glycoprotein non-metastatic protein B (GPNMB) promotes bone metastasis (BM) in various types of cancer. However, GPNMB expression and its function in patients with renal cell carcinoma (RCC) and BM is still unknown. Therefore, the clinical significance of GPNMB and its biological function in RCC with BM was investigated in the present study. A total of 31 patients with RCC and BM were retrospectively collected. The association between GPNMB protein expression level on the primary tumor and the clinicopathological characteristics of the patients was analyzed. Kaplan-Meier analysis was used to investigate the association between GPNMB expression and the prognosis of the patients. The effects of GPNMB inhibition on cell proliferation, migration and invasion in RCC cells were investigated using short hairpin (sh)RNA. High GPNMB expression level was significantly associated with the number $(\mathrm{P}=0.001)$ and the extent of $\mathrm{BM}(\mathrm{P}=0.001)$, Fuhrman grade $(\mathrm{P}=0.037)$, and ERK expression level $(\mathrm{P}=0.003)$ of the primary tumor. In addition, GPNMB overexpression was significantly associated with poor prognosis with respect to overall survival time $(\mathrm{P}=0.001)$. Furthermore, a specific shRNA sequence targeting the GPNMB gene was constructed and transduced into the ACHN cell line, using a lentivirus vector to obtain a stable cell line with low mRNA expression level of GPNMB. Low GPNMB expression level inhibited RCC cell proliferation, which was measured using a Cell Counting Kit-8 assay. Cell migration and invasion ability was significantly decreased in GPNMB knockdown RCC cells compared with that in cells transduced with the negative control shRNA. In addition, the protein expression levels of phosphorylated ERK were lower in
\end{abstract}

Correspondence to: Dr Li-Bo Man or Dr Jian-Po Zhai, Department of Urology, Beijing Jishuitan Hospital, 68 Huinanbei Road, Beijing 102200, P.R. China

E-mail: jstmnwk@126.com

E-mail: dczhaijp@126.com

Abbreviations: GPNMB, glycoprotein non-metastatic protein B; RCC, renal cell carcinoma; BM, bone metastasis; CCK, Cell Counting Kit; ORR, objective response rate; PFS, progression-free survival

Key words: bone metastasis, ERK, GPNMB, prognosis, RCC the GPNMB shRNA-transduced ACHN cells compared with those in the control cells. Therefore, these results suggested that GPNMB plays an important role in tumor progression in RCC with BM. Furthermore, it might serve as a predictive marker for BM and as a poor prognostic factor in RCC with BM. GPNMB downregulation suppressed the proliferation, migration and invasion of the RCC cells, which may be mediated through the inhibition of the ERK signaling pathway.

\section{Introduction}

Renal cell carcinoma ( $\mathrm{RCC}$ ) is a common urinary system malignant tumor and accounts for 2-3\% of adult malignant tumors. The male to female ratio was $\sim 1.5: 1$ and the 50-70 years old age group had the highest prevalence $(1,2)$. The incidence rate of RCC is increasing $2.5 \%$ each year $(3,4)$. One-third of patients with RCC have metastasis at initial diagnosis and up to $40 \%$ of patients with initially localized RCC eventually develop metastasis during follow-up (5-7). The common sites of metastasis from RCC are the lungs (45.2\%), followed by the bone $(29.5 \%)$, regional lymph nodes $(21.8 \%)$, the liver $(20.3 \%)$, the adrenal gland $(8.9 \%)$ and the brain $(8.1 \%)(8)$. Molecular-targeted therapies are the leading treatment for metastatic RCC (mRCC). However, the objective response rate (ORR) and complete response of the primary tumor was only 28 and $2.5 \%$, respectively in patients treated with first-line targeted therapy (9). In addition, the prognosis of patients with mRCC was found to be extremely poor, with a 5-year survival rate of $<10 \%(10)$. Therefore, it is important to identify novel prognostic, diagnostic and therapeutic methods to increase the understanding of the development and progression of RCC.

Glycoprotein non-metastatic protein B (GPNMB) is a type I transmembrane protein, which was first isolated and described in 1995 (11). The GPNMB gene is located on chromosome 7q15 and encodes a protein, 572 amino acids in length (12). GPNMB has been found to be expressed in different tissues and cells, including bone tissues, osteoclasts, osteoblasts, macrophages and dendritic cells. It plays diverse and important roles in normal cells and tissues, such as cell differentiation and migration, and tissue regeneration and inflammation (13-15). However, the overexpression of GPNMB has been found in different types of cancer and was found to increase the invasion and metastasis in several types of tumor cells. GPNMB promoted the metastasis of melanoma, glioblastoma and hepatocellular carcinoma (16-18). In addition, 
the increased expression of GPNMB, both at the mRNA and protein expression level, was detected in osteosarcoma tissues compared with that in the adjacent non-cancerous tissues (19). Furthermore, GPNMB promoted the development of an aggressive, pro-metastatic phenotype in human prostate cancer cell lines (20), and GPNMB overexpression in breast cancer cells was associated with bone invasion (21). These previous studies suggested that GPNMB may play an important role in the bone metastasis (BM) of malignant tumors, which could serve as a potential therapeutic target.

Therefore, the aim of the current study was to quantify the protein expression levels of GPNMB in the primary renal tumor and the matched BM, to investigate the association between GPNMB expression level and the clinicopathological parameters and prognosis in patients with RCC and BM. Furthermore, the results of our previous research found that the expression level of ERK was significantly increased in the matched BM compared with that in the primary RCC (22). Therefore, the underlying molecular mechanism of GPNMB activity in tumor metastasis, particularly via the activation of the ERK pathway, was also investigated.

\section{Materials and methods}

Tissue samples and cell lines. In the present retrospective study, a total of 31 patients with RCC and BM were collected. The present study was approved by the Ethical Committee of Beijing Jishuitan Hospital (approval no. 2016-16; Beijing, China). Due to the retrospective design of the study patient consent was not required for data analysis and all samples were anonymized prior to analysis. The samples included primary RCC and the matched BM, which were resected during surgery. The following inclusion criteria were used: Patients with i) newly diagnosed BM from RCC; ii) BM diagnosed using a bone scan or positron emission tomography-CT and iii) definite pathological diagnosis of the BM. The exclusion criteria included patients with i) concomitant other malignant tumors; ii) no surgical treatment of BM and iii) targeted therapy or radiotherapy.

Information regarding the sex, age, time, extent and the number of BMs, the presence or absence of visceral metastasis, and the pathological type of BM was also collected from patient records. All the patients were followed up regularly following surgery, at 3-month intervals during the first 2 years then, at 6-month intervals thereafter. Chest X-rays, chest CT scans and serum chemistry analyses (blood biochemistry and routine blood analysis) was performed for all the patients at every follow-up visit. Recurrence was evaluated from the patient records at Beijing Jishuitan Hospital (Beijing China) and the patients were followed up by their physician until they died or until the date of the last documented contact.

According to the time of $\mathrm{BM}$, the patients were divided into 2 groups: RCC with synchronous BM and RCC with metachronous BM groups. The patients who had BM at initial diagnosis of RCC were defined as the BM synchronous group. The patients diagnosed with BM after the diagnosis of RCC were defined as the BM metachronous group. With respect to the extent of the BM, the patients were divided into 3 groups: axial only BM, appendicular only BM, and both axial and appendicular BM groups.
The human ACHN RCC-derived cell line was purchased from the National Infrastructure of Cell Line Resource. The cells were maintained in MEM containing $10 \%$ fetal bovine serum (FBS, both Gibco; Thermo Fisher Scientific, Inc.) at $37^{\circ} \mathrm{C}$ in a humidified incubator with $5 \% \mathrm{CO}_{2}$.

Immunohistochemistry. All the paraffin-embedded sections (4- $\mu \mathrm{m}$ thick) were dewaxed in xylene for $5 \mathrm{~min}$ three times followed by $100 \%$ alcohol for $5 \mathrm{~min}, 90 \%$ alcohol for $5 \mathrm{~min}$ and $80 \%$ alcohol for $5 \mathrm{~min}$. The sections were then rinsed in distilled water for $2 \mathrm{~min}$ and the antigen was retrieved (0.01 M citrate buffer, $\mathrm{pH} 6.0$ ) at $95^{\circ} \mathrm{C}$ for $20 \mathrm{~min}$. Endogenous peroxidase activity was blocked with $3 \%$ hydrogen peroxide, then non-specific binding was blocked with $5 \%$ normal goat serum (cat. no. AR1009; Boster Biological Technology) for $30 \mathrm{~min}$ at room temperature. Following which, the sections were incubated with the primary rabbit anti-human GPNMB (1:500 dilution; cat. no. ab222109) and ERK antibodies (1:300 dilution; cat. no. ab32537) (both from Abcam) at $4^{\circ} \mathrm{C}$ overnight in a wet box. Subsequently, the sections were incubated with the biotinylated secondary antibody (1:200 dilution; cat. no. K5007; Dako; Agilent Technologies, Inc.) for $20 \mathrm{~min}$ at room temperature, then with the chromogen, 3,3'-diaminobenzidine for $5 \mathrm{~min}$ at room temperature. The sections were lastly stained with Mayer's hematoxylin (cat. no. H9627; Sigma-Aldrich; Merck KGaA) for $3 \mathrm{~min}$ at room temperature and viewed under a microscope (Olympus BX53; Olympus Corporation) with $\mathrm{x} 400$ magnification.

At least 500 tumor cells were evaluated for immunostaining, and the GPNMB or ERK expression level was evaluated according to the staining intensity and the percentage of cells expressing GPNMB or ERK. Briefly, the sections were evaluated for the percentage of stained cells using the following criteria: $0,0 \% ; 1,<10 \% ; 2,11-50 \% ; 3,51-80 \%$ and $4,>80 \%$. At the same time, the intensity of staining was also evaluated and graded from 1 to 3 , as follows: 0 , negative; 1 , weak; 2 , moderate; and 3 , strong. The two values obtained were multiplied together to calculate a receptor score (maximum value, 12). The tumor samples that scored $\leq 6$ were considered to have a low expression level of GPNMB (GPNMB low; $\mathrm{n}=20$ ), whereas samples which scored $>6$ were classified as having a high expression level of GPNMB (GPNMB high; $\mathrm{n}=11$ ). To decrease the interobserver variation in evaluating the staining patterns, the immunohistochemical staining was evaluated and scored by two independent observers using the semi-quantitative method. Any discrepancies were resolved by a joint review using a double-headed light microscope (Axioplan II; Zeiss AG).

RNA interference. Small interfering (si)RNA targeting human GPNMB mRNA (5'-GGAATACAACCCAATAGA-3') was ligated into the lentiviral vector pLVshRNA-EGFP(2A)Puro $(0.1 \mu \mathrm{g}$; Inovogen Tech) using the restriction sites, EcoRI and BamHI. The lentivirus was made using the 293T cells transduced with pLVshRNA-GFP, psPAX2 (cat. no. 12260; Addgene, Inc.) and pMD2.G (cat. no. 12259; Addgene, Inc.) at a $4: 3: 2$ ratio. The cells were incubated at $37^{\circ} \mathrm{C}$ in a humidified incubator with $5 \% \mathrm{CO}_{2}$, for $48 \mathrm{~h}$, then the medium was collected and filtered using a $0.45 \mu \mathrm{M}$ filter unit. The ACHN cell line was transduced with a high multiplicity of infection 
and $10 \mu \mathrm{g} / \mathrm{ml}$ polybrene. The samples were analyzed $72 \mathrm{~h}$ following transduction using flow cytometry (FACS AriaIII; BD Biosciences) to sort the $\mathrm{GFP}^{+}$cells. $\mathrm{GFP}^{+}$cells with puromycin (cat. no. A1113803; Thermo Fisher Scientific, Inc.) resistance were used for further analysis. The concentrations of puromycin used for selection and maintenance were 1 and $0.5 \mu \mathrm{g} / \mathrm{ml}$, respectively. A non-targeting sequence (5'-UUCUCCGAACGUGUCACGU-3'; Invitrogen; Thermo Fisher Scientific, Inc.) was used as the negative control (NC).

Western blot analysis. The cells were lysed with RIPA buffer, containing $20 \mathrm{mM}$ Tris- $\mathrm{HCl}$ (pH 7.4), $150 \mathrm{mM}$ sodium chloride, $1 \mathrm{mM}$ dithiothreitol, $5 \mathrm{mM}$ EDTA and $1 \%$ (w/v) Triton X-100 at $4^{\circ} \mathrm{C}$ for $30 \mathrm{~min}$. The lysates were then centrifuged at $12,000 \mathrm{x} \mathrm{g}$ at $4^{\circ} \mathrm{C}$ for $20 \mathrm{~min}$. The supernatant was collected and the protein concentration was calculated using a BCA assay (Pierce; Thermo Fisher Scientific, Inc.). Total protein (30 ug) was separated using 10\% SDS-PAGE, then transferred to PVDF membranes (cat. no. IPVH00010; Merck KGaA) and incubated overnight at $4{ }^{\circ} \mathrm{C}$ with the primary antibodies ( $\beta$-actin, 1:5,000; cat. no. sc-47778; Santa Cruz Biotechnology, Inc.; GPNMB, 1:1,000; cat. no. ab227695; Abcam; ERK, 1:1,000; cat. no. 9102; Cell Signaling Technology, Inc.; and phosphorylated (p)-ERK, 1:500; cat. no. 3179; Cell Signaling Technology, Inc.). Next, $5 \%$ skimmed milk powder in TBS [25 mM Tris, 0.15M NaCl (pH 7.2-7.5)] was used for blocking at room temperature for $1 \mathrm{~h}$. The membranes were then incubated with the HRP-linked secondary antibody (1:5,000 dilution; cat. no. 7074; Cell Signaling Technology, Inc.) for $1 \mathrm{~h}$ at $37^{\circ} \mathrm{C}$. The signal was detected using a SuperSignal West Pico PLUS Chemiluminescent Substrate (Thermo Fisher Scientific, Inc.).

Cell proliferation assays. In vitro proliferation was analyzed using a Cell Counting Kit (CCK-8; Shanghai Yeasen Biotechnology Co., Ltd.). The cells were seeded at a density of 4,000 cells/well in 96-well plates. Following which, $10 \mu \mathrm{l} /$ well CCK-8 reagent was added $0,24,48,72$ and $96 \mathrm{~h}$ later and the cells were incubated for $3 \mathrm{~h}$ at $37^{\circ} \mathrm{C}$. The optical density was measured at $450 \mathrm{~nm}$ using a microplate reader (Tecan Group, Ltd.). The experiment was repeated 5 times.

Cell migration and invasion assays. Matrigel invasion assays were performed at $37^{\circ} \mathrm{C}$ for $16 \mathrm{~h}$ using 24 -well Transwell inserts (Corning, Inc.) coated with $30 \mu \mathrm{g}$ Matrigel (BD Biosciences). The cells $(50,000)$ suspended in $200 \mu 1$ serum-free DMEM were seeded into the upper chamber and $600 \mu 1$ NIH-3T3 conditioned medium (CM) was placed in the lower chamber. Following incubation at $37^{\circ} \mathrm{C}$ for $24 \mathrm{~h}$, the cells were fixed with $4 \%$ paraformaldehyde (Sinopharm Chemical Reagent Co., Ltd.) at room temperature for $10 \mathrm{~min}$, and then stained with $0.5 \%$ crystal violet (Beyotime Institute of Biotechnology) at room temperature for $10 \mathrm{~min}$. The cells that had invaded through the membrane were counted at x200 magnification under a light microscope and normalized relative to the 10,000 seeded cells. Transwell cell migration assays were performed using the same method; however, the cells were only incubated for $5 \mathrm{~h}$ and without Matrigel. CM from the NIH-3T3 cell line (cat. no. CRL-1658; American Type Culture Collection) was maintained in DMEM and cultured in a humidified incubator
Table I. Clinicopathological features in the patients with renal cell carcinoma and bone metastasis.

\begin{tabular}{lr} 
Clinicopathological feature & Number $(\%)$ \\
\hline Sex & \\
Male & $22(70.9)$ \\
Female & $9(29.1)$ \\
Time of bone metastasis & \\
Synchronous & $17(54.8)$ \\
Metachronous & $14(45.2)$ \\
Number of bone metastasis & \\
Solitary & $16(51.6)$ \\
Multiple & $15(48.4)$ \\
Extent of bone metastasis & \\
Axial only & $13(41.9)$ \\
Appendicular only & $12(38.7)$ \\
Both axial and appendicular & $6(19.4)$ \\
Visceral metastasis & \\
Yes & $9(29.1)$ \\
No & $22(70.9)$ \\
Pathology of primary tumor & \\
Clear cell carcinoma & $29(93.5)$ \\
Non-clear cell carcinoma & $2(6.5)$ \\
Fuhrman grade of primary tumor & \\
II & $12(38.7)$ \\
III & $16(51.6)$ \\
IV & \\
&
\end{tabular}

at $37^{\circ} \mathrm{C}$ with $5 \% \mathrm{CO}_{2}$, collected, according to the following process, and used as a chemoattractant: NIH-3T3 cells were grown to $50 \%$ confluency. The medium was then changed to fresh serum-free medium and the cells were incubated for an additional $48 \mathrm{~h}$. The conditioned media was drawn off the cells and centrifuged at $25^{\circ} \mathrm{C}$ for $5 \mathrm{~min}$ at $200 \mathrm{x}$ g to remove debris, and stored at $-20^{\circ} \mathrm{C}$.

Statistical analysis. Measurement data are expressed as mean \pm standard deviation, and enumeration data are shown as $n(\%)$. All experiments were independently repeated three times. Associations between the clinicopathological parameters and GPNMB expression level were analyzed using a Fisher's exact test, while the association between the expression level of ERK and the GPNMB high and low expression level groups was analyzed using an unpaired Student's t-test, and the expression level of GPNMB and ERK in the primary renal tumor and matched BM was analyzed using a paired Student's t-test. Survival curves were analyzed using the Kaplan-Meier method for patients with GPNMB high or low expression levels and were evaluated for statistical significance using the log-rank test. Overall survival was analyzed in patients separated according to number of BM, extent of $\mathrm{BM}$ and visceral metastasis. Univariate and multivariate Cox regression analyses were performed to assess the associations between clinical covariates and survival. $\mathrm{P}<0.05$ was used to 
Table II. Association between GPNMB expression level in the primary tumor and clinicopathological features.

\begin{tabular}{|c|c|c|c|}
\hline \multirow[b]{2}{*}{ Clinicopathological feature } & \multicolumn{2}{|c|}{ GPNMB expression level } & \multirow[b]{2}{*}{ P-value } \\
\hline & High & Low & \\
\hline Sex, $n$ & & & 0.606 \\
\hline Male & 8 & 14 & \\
\hline Female & 3 & 6 & \\
\hline Time of bone metastasis, $\mathrm{n}$ & & & 0.707 \\
\hline Synchronous & 7 & 10 & \\
\hline Metachronous & 4 & 10 & \\
\hline Number of bone metastasis, $\mathrm{n}$ & & & 0.001 \\
\hline Solitary & 1 & 15 & \\
\hline Multiple & 10 & 5 & \\
\hline Extent of bone metastasis, $n$ & & & 0.001 \\
\hline Axial only & 4 & 9 & \\
\hline Appendicular only & 1 & 11 & \\
\hline Both axial and appendicular & 6 & 0 & \\
\hline Visceral metastasis, $\mathrm{n}$ & & & 0.217 \\
\hline Yes & 5 & 4 & \\
\hline No & 6 & 16 & \\
\hline Fuhrman grade of primary tumor, $n$ & & & 0.037 \\
\hline II & 1 & 11 & \\
\hline III & 8 & 8 & \\
\hline IV & 2 & 1 & \\
\hline ERK expression level $^{\mathrm{a}}$ & $7.25 \pm 2.55$ & $2.47 \pm 0.64$ & 0.003 \\
\hline
\end{tabular}

${ }^{a}$ Mean \pm SD. GPNMB, glycoprotein non-metastatic protein B.

indicate a statistically significant difference. All statistical analyses were performed using the SPSS software program (v23.0; IBM Corp.).

\section{Results}

Clinicopathological features of RCC with BM. The clinicopathological features of the 31 patients with RCC and BM, enrolled into the present study are summarized in Table I. RCC with BM was more common in males $(70.9 \%$; $\mathrm{n}=22)$ compared with that in females, and the male to female ratio of 2.44:1. The median age was 59 years (range, 38-75 years). Synchronous $\mathrm{BM}$ was found in 17 patients $(54.8 \%)$. A total of 16 patients $(51.6 \%)$ had solitary BM. There were 13, 12 and 6 patients in the axial only BM, appendicular only BM, and both axial and appendicular BM groups, respectively. Only 9 patients $(29.1 \%)$ had visceral metastasis. The most common pathology was clear cell carcinoma, which was found in 29 patients $(93.5 \%)$.

Expression analysis of GPNMB in patients RCC with BM. High GPNMB protein expression level in the primary tumor was detected in $11(35.5 \%)$ out of the 31 patients with RCC and BM using immunohistochemistry, where it was found in the membrane (Fig. 1A). The association between GPNMB expression and the clinicopathological characteristics was subsequently analyzed (Table II). High GPNMB expression
Table III. Protein expression level of GPNMB and ERK in the primary renal tumor and matched bone metastasis.

\begin{tabular}{lccc}
\hline Gene name & Primary tumor & Bone metastasis & P-value \\
\hline GPNMB & $3.65 \pm 1.87$ & $6.91 \pm 3.68$ & 0.001 \\
ERK & $3.96 \pm 1.36$ & $6.52 \pm 3.15$ & 0.016 \\
\hline
\end{tabular}

GPNMB, glycoprotein non-metastatic protein B.

level was associated with the number $(\mathrm{P}=0.001)$ and the extent of $\mathrm{BM}(\mathrm{P}=0.001)$, Fuhrman grade $(\mathrm{P}=0.037)$, and ERK protein expression level $(\mathrm{P}=0.003)$ in the primary tumor. GPNMB expression was not associated with sex $(\mathrm{P}=0.606)$, time of $\mathrm{BM}$ $(\mathrm{P}=0.707)$ or visceral metastasis $(\mathrm{P}=0.217)$. The protein expression level of GPNMB and ERK was significantly increased in the matched $\mathrm{BM}$ compared with that in the primary tumor ( $\mathrm{P}=0.001$ and $\mathrm{P}=0.016$, respectively) (Table III; Fig. 1).

Association between GPNMB expression level and prognosis in patients with RCC and BM. Kaplan-Meier analysis was used to investigate the association between GPNMB protein expression level and patient prognosis. High GPNMB protein expression level was significantly associated with a poor 

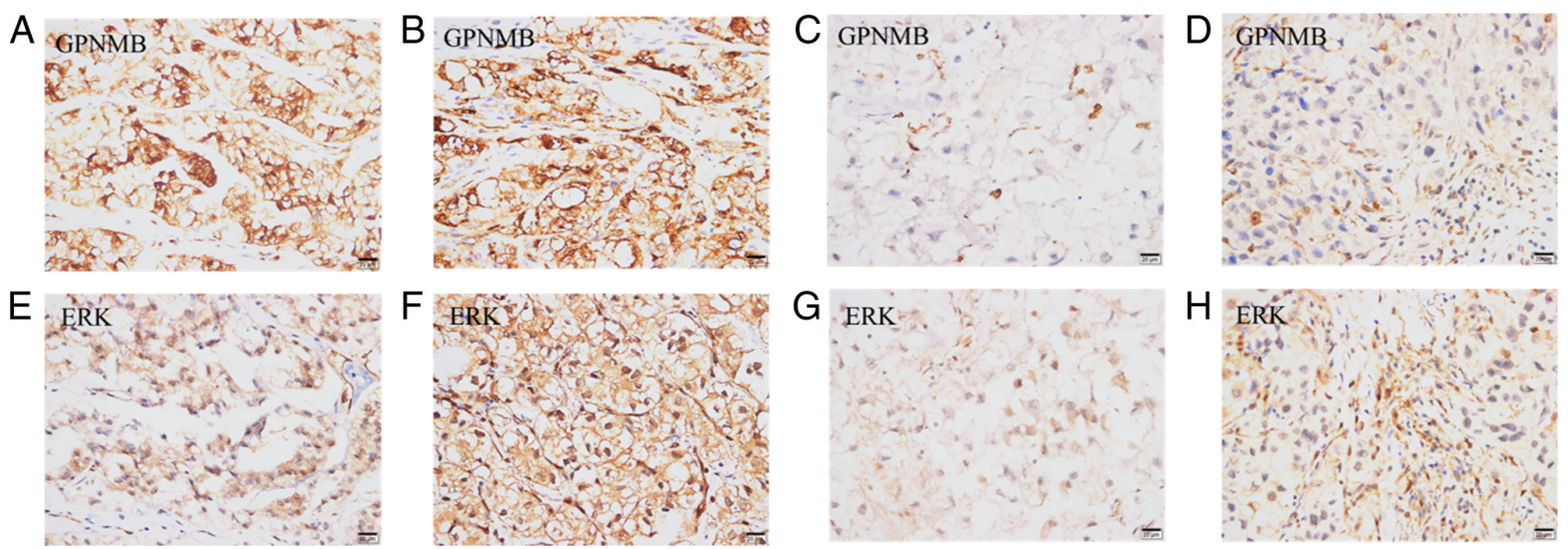

Figure 1. Immunohistochemical analysis of GPNMB and ERK in the primary renal tumor and the matched BM in patients with renal cell carcinoma. (A) High and (C) low GPNMB expression in the primary renal tumor and (B and D) increased GPNMB expression in the matched BM. (E) High and (G) low ERK expression in the primary renal tumor and ( $\mathrm{F}$ and $\mathrm{H}$ ) increased ERK expression in the matched BM. Magnification, x400. GPNMB, glycoprotein non-metastatic protein B; BM, bone metastasis.

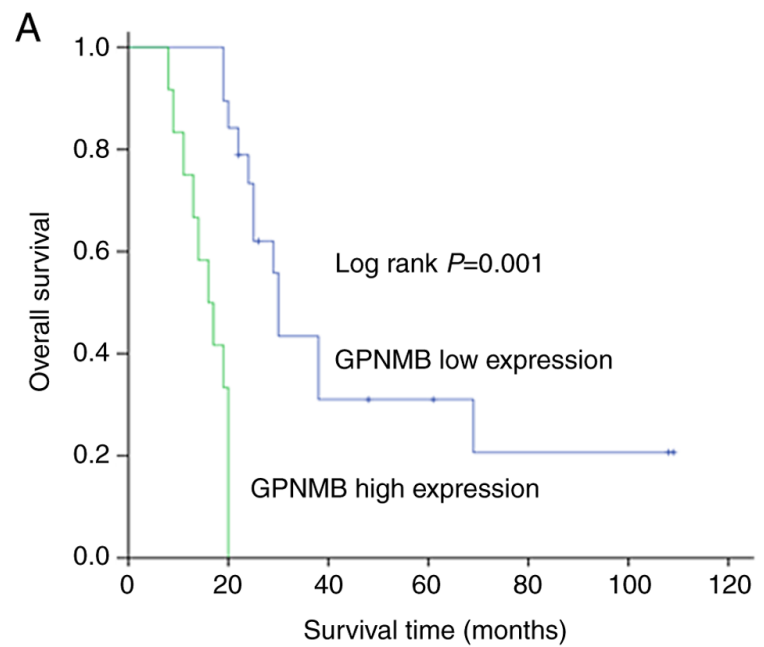

C

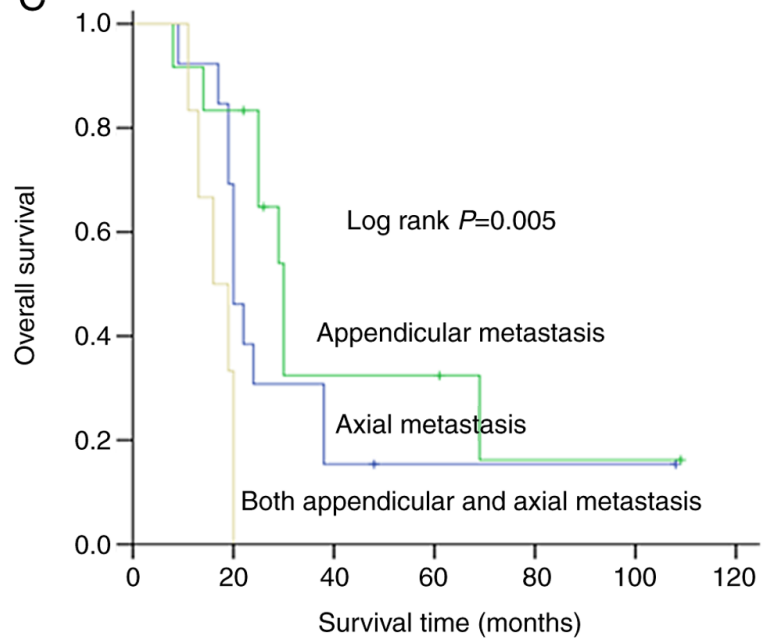

B

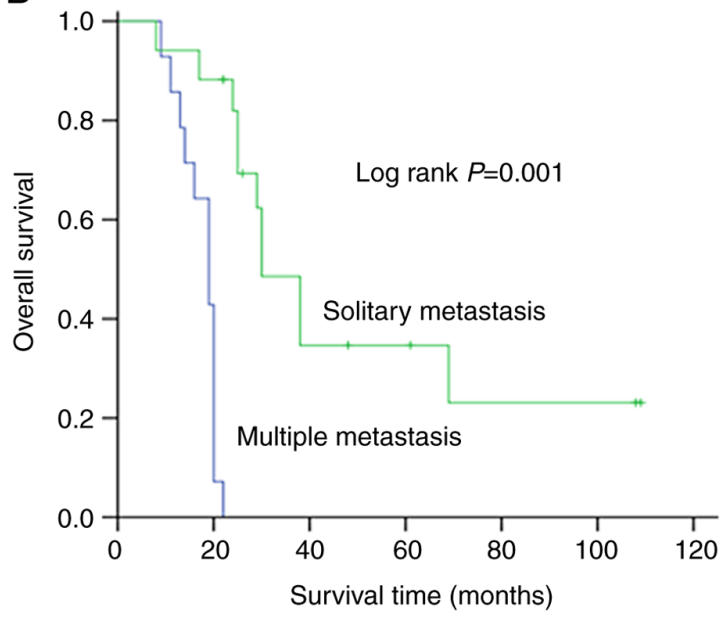

D

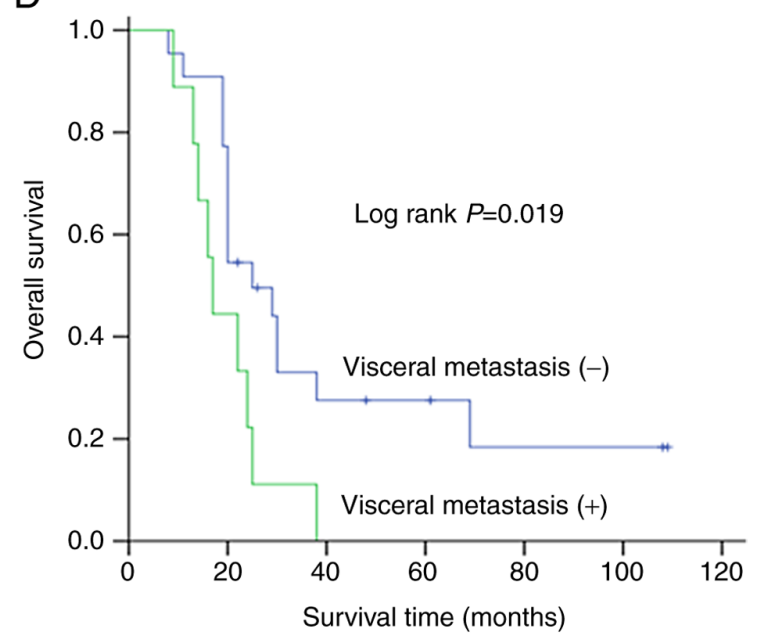

Figure 2. Kaplan-Meier survival curves for patients with RCC and BM. Patients with (A) GPNMB high expression level, (B) multiple BM, (C) both appendicular and axial metastasis and (D) visceral metastasis showed poor prognosis. BM, bone metastasis; GPNMB, glycoprotein non-metastatic protein B.

prognosis (log-rank test, $\mathrm{P}=0.001$; Fig. 2A). Overall survival time was also analyzed using Kaplan-Meier method in patients separated by number (Fig. 2B) and extent of BM (Fig. 2C), and visceral metastasis (Fig. 2D). Univariate and multivariate analyses were performed using the Cox proportional hazards model (Table IV) and the results from the univariate analysis revealed that GPNMB protein expression level, the number $(\mathrm{P}=0.001)$ and extent of $\mathrm{BM}(\mathrm{P}=0.005)$, and visceral metastasis 
Table IV. Univariate and multivariate analysis of factors associated with survival time in 31 patients with renal cell carcinoma and bone metastasis.

\begin{tabular}{|c|c|c|c|c|}
\hline \multirow[b]{2}{*}{ Clinicopathological feature } & \multicolumn{2}{|c|}{ Univariate analysis } & \multicolumn{2}{|c|}{ Multivariate analysis } \\
\hline & HR $(95 \%$ CI $)$ & P-value & HR (95\% CI) & P-value \\
\hline \multicolumn{5}{|l|}{ Sex } \\
\hline $\begin{array}{l}\text { Male } \\
\text { Female }\end{array}$ & $1.05(0.43-2.52)$ & 0.919 & & \\
\hline \multicolumn{5}{|l|}{ Time of bone metastasis } \\
\hline $\begin{array}{l}\text { Synchronous } \\
\text { Metachronous }\end{array}$ & $1.21(0.41-2.06)$ & 0.833 & & \\
\hline \multicolumn{5}{|l|}{ Number of bone metastasis } \\
\hline $\begin{array}{l}\text { Solitary } \\
\text { Multiple }\end{array}$ & $5.49(2.14-12.76)$ & 0.001 & $1.30(1.02-1.76)$ & 0.044 \\
\hline \multicolumn{5}{|l|}{ Extent of bone metastasis } \\
\hline $\begin{array}{l}\text { Axial only } \\
\text { Appendicular only } \\
\text { Both axial and appendicula }\end{array}$ & $10.61(6.21-18.56)$ & 0.005 & $1.02(0.56-1.87)$ & 0.949 \\
\hline \multicolumn{5}{|l|}{ Visceral metastasis } \\
\hline $\begin{array}{l}\text { Yes } \\
\text { No }\end{array}$ & $2.54(1.09-5.89)$ & 0.019 & $3.65(1.14-11.56)$ & 0.029 \\
\hline \multicolumn{5}{|c|}{ Fuhrman grade of primary tumor } \\
\hline $\begin{array}{l}\text { II } \\
\text { III } \\
\text { IV }\end{array}$ & $2.29(1.18-4.43)$ & 0.014 & $1.01(0.35-2.95)$ & 0.972 \\
\hline GPNMB expression level & $12.59(3.52-45.13)$ & 0.001 & $5.68(1.09-29.44)$ & 0.039 \\
\hline
\end{tabular}

$(\mathrm{P}=0.019)$ were significant indicators of poor overall survival time. All the significant variables identified from the univariate analysis were included in the multivariant analysis Cox regression model to identify the independent prognostic factors. The results showed that visceral metastasis $(\mathrm{P}=0.029)$, number of $\mathrm{BM}(\mathrm{P}=0.044)$ and $\mathrm{GPNMB}$ protein expression level $(\mathrm{P}=0.039)$ were independent prognosis factors for patients with $\mathrm{RCC}$ and BM (Table IV).

Effect of GPNMB downregulation on proliferation in the $R C C$ cells. The effects of GPNMB silencing on RCC cell proliferation were investigated using shRNA. Western blot analysis showed that the protein expression level of GPNMB was suppressed following transduction with shRNA (Fig. 3A). To investigate the possible antiproliferative effects of GPNMB knockdown, a CCK-8 was performed 4 days following the transduction of shRNA. Cell proliferative ability was significantly decreased in the GPNMB knockdown group compared with that in the NC group (Fig. 3B).

Effect of GPNMB downregulation on cell migration and invasion. To investigate the invasion and migration abilities of the GPNMB knockdown RCC cells, Transwell and Matrigel assays were performed (Fig. 3C). The results from the Transwell assay revealed that, following transduction with
GPNMB shRNA, the migration ability of the ACHN cell line was significantly inhibited (Fig. 3D) compared with that in the cells transduced with siNC. In addition, the results from the Matrigel assay revealed that the number of invasive cells in the GFP-shRNA-GPNMB group was significantly lower compared with that in the GFP-NC group (Fig. 3D).

Effect of GPNMB inhibition on the ERK signaling pathway. ERK plays a critical role in tumor cell survival and proliferation (23). Therefore, it was investigated whether GPNMB could affect Ras signaling via the ERK signaling pathway. The results indicated that the expression levels of phosphorylated ERK were lower in the GPNMB shRNA-transduced ACHN cells compared with those in the control cells (Fig. 3A).

\section{Discussion}

In the present study, the clinicopathological significance of GPNMB protein expression level in patients with RCC and BM was investigated. The immunohistochemical analysis showed that high protein GPNMB expression level was detected in 11 (35.5\%) out of 31 patients with RCC and BM. In addition, GPNMB protein expression level was also associated with the number and the extent of BM. Furthermore, compared with that in the primary renal tumor, the protein expression level 

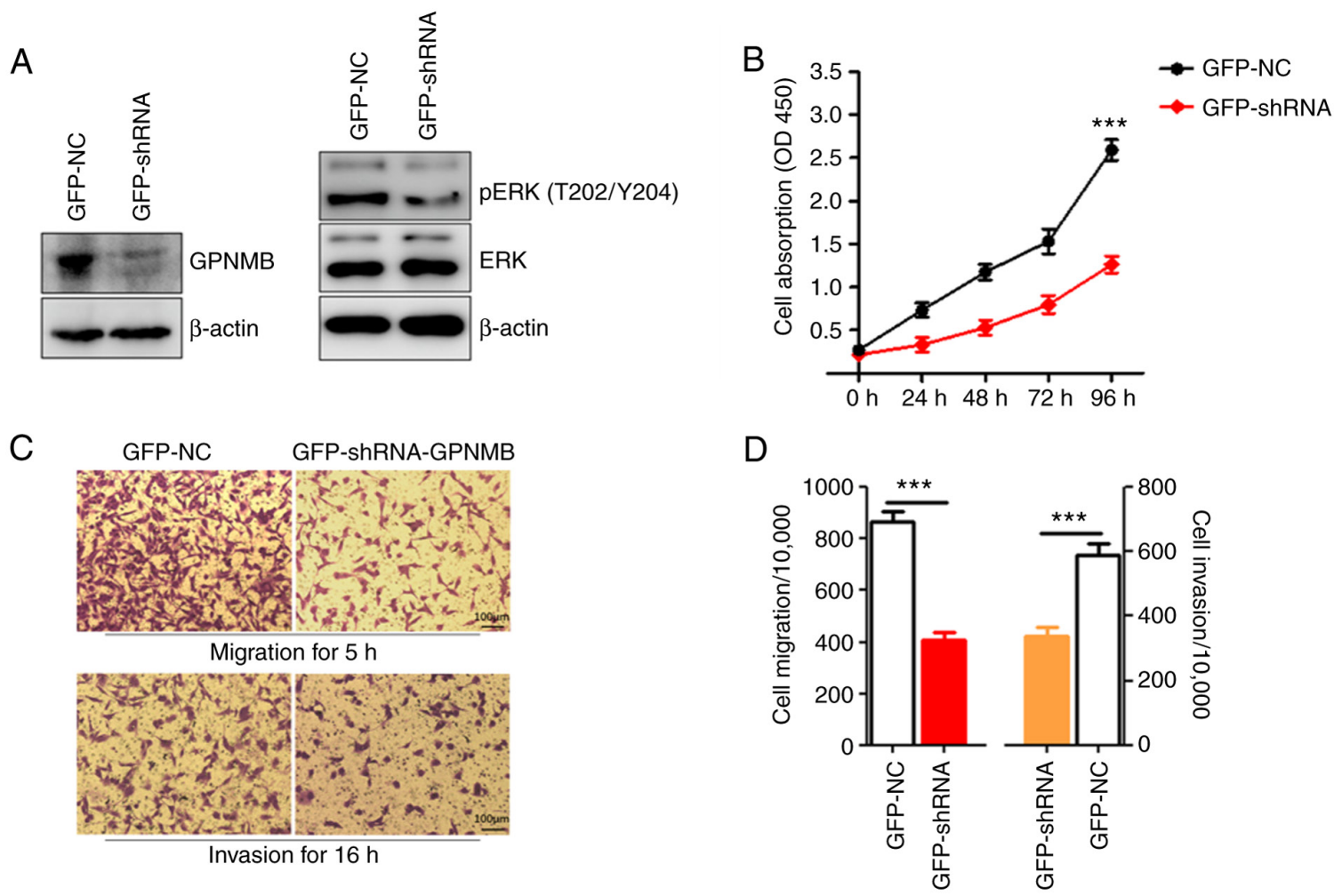

Figure 3. Effect of GPNMB downregulation. (A) Western blot analysis of GPNMB, ERK and p-ERK protein expression level in ACHN cells transduced with GPNMB shRNA and NC shRNA. (B) Effects of GPNMB knockdown on the proliferation of the ACHN cells following transduction with GPNMB shRNA and NC shRNA. Cell proliferation was assessed using a Cell Counting Kit assay at 24, 48, 72 and 96 h. (C) Migration and invasion assay of the ACHN cells transduced with GPNMB shRNA and NC shRNA, and the results were (D) quantitatively analyzed. ${ }^{* * *} \mathrm{P}<0.0001$. GPNMB, glycoprotein non-metastatic protein $\mathrm{B}$; sh, short hairpin; p, phosphorylated; $\mathrm{NC}$, negative control.

of GPNMB in the matched BM was significantly increased. These findings are consistent with the results from the study by Qin et al (24) and validate the hypothesis that bone metastasized RCC, with a high expression level of GPNMB, could be the result of a more invasive subclone derived from the primary tumor. The results of the studies by Rose et al in 2007 (25) and 2010 (26) revealed that overexpression of GPNMB significantly enhanced the formation of osteolytic bone metastases from breast cancer; therefore, GPNMB has been identified as a bone metastatic promotor and a new target for the treatment of breast cancer. This finding demonstrated that high GPNMB expression level was associated with enhanced bone metastatic capacities of cancer cells.

GPNMB has emerged as an immunomodulator and an important positive mediator of tumor progression and metastasis in numerous types of solid cancer $(13,27)$. As shown in the Kaplan-Meier curves, patients with high GPNMB expression levels had worse overall survival time compared with that in patients with low GPNMB expression levels. In addition, it was confirmed that the number and extent of BM, and visceral metastasis was associated with the survival times of patients with RCC and BM. Furthermore, multivariate Cox regression analysis revealed that GPNMB expression, visceral metastasis and the number of $\mathrm{BM}$ were independent prognostic factors for RCC survival. This is consistent with a previous study, which demonstrated that high GPNMB expression level was an independent prognostic factor and may serve as a novel therapeutic target in breast cancer (28). Similarly, overexpression of GPNMB was also detected in patients with small cell lung cancer and poor prognosis (29). In addition, Kaplan-Meier analysis demonstrated that upregulated GPNMB expression was associated with an unfavorable prognosis for patients with epithelial ovarian cancer (30). Based on these results, GPNMB protein expression could be an unfavorable independent prognostic biomarker for patients with RCC and BM.

The functional significance of GPNMB overexpression in cancer requires further investigation. GPNMB may promote $\mathrm{BM}$ in cancer cells via a variety of molecular mechanisms. The effect of GPNMB inhibition on the ERK signaling pathway was analyzed in the present study. The results indicated that the protein expression levels of phosphorylated ERK were lower in the cells with GPNMB knocked out compared with those in the control cells. Furthermore, the invasive and migratory abilities of the GPNMB-silenced ACHN cells were also significantly decreased. These findings demonstrated that GPNMB may promote RCC cell growth and metastasis via the ERK signaling pathway. However, other mechanisms may also be involved in GPNMB-mediated metastasis $(16,27,31,32)$. GPNMB promoted the aggressive phenotypes of prostate cancer cell lines by inducing MMP-2 and MMP-9, which may represent another mechanism by which GPNMB promoted tumor metastasis to the bone (20). In addition, overexpression of GPNMB in breast epithelial cells induced epithelial-mesenchymal transition and promoted tumor formation and invasion in mice (33). GPNMB was also found to contribute to the acquisition of stem cell-like properties in dormant breast cancer cells, which could support tumor cell survival, extravasation, and cause the process of metastasis 
more efficient (34). Previously, GPNMB was identified as a negative regulator of $\mathrm{T}$ cell activation. GPNMB promoted the growth and metastasis of melanoma, and drove tumor progression and metastasis by downregulating the activation of melanoma-reactive T cells (18). Furthermore, GPNMB expression may facilitate the systemic antitumor responses and mediated effects on angiogenesis in breast cancer cells (33). Therefore, the biological roles of GPNMB on RCC progression and $\mathrm{BM}$ requires further investigation.

GPNMB has become an attractive therapeutic target due to its overexpression in a variety of cancers. Glembatumumab vedotin, an antibody-drug conjugate, which targets GPNMB, is in clinical trials as a single agent in multiple types of cancer, such as advanced melanoma and breast cancer (18,35-37). The results of several phase II clinical trials showed that glembatumumab vedotin had modest inhibitory activity in patients with advanced melanoma. The ORR was $11-33 \%$, the median response duration was $\sim 6.0$ months, the median progression-free survival (PFS) time was 4.4 months and the median overall survival time was 9.0 months $(38,39)$. The activity of glembatumumab vedotin in patients with advanced breast cancer and high GPNMB expression has also been investigated in several phase II studies. Significantly higher ORR and longer PFS times were found in the GPNMB overexpression group. The ORR to glembatumumab vedotin therapy in patients with advanced breast cancer and high GPNMB expression levels was $30-40 \%$, while the ORR was only $9 \%$ in the chemotherapy group (40). In a phase II clinical trial where the patients with treatment-resistant metastatic breast cancer received glembatumumab vedotin, the median PFS time was 9.1 weeks for all patients and 18.0 weeks for patients with GPNMB-positive tumors (41). However, there has been no clinical trial to investigate the effects of glembatumumab vedotin in patients with RCC and BM; therefore, further investigation is required.

In conclusion, the results from the current study suggested that upregulated GPNMB expression was associated with the extent of BM and poor prognosis, indicating that GPNMB may serve as a potential prognostic marker for patients with RCC and BM. GPNMB downregulation suppressed the proliferation, migration and invasion of the RCC cell line, which may be mediated via the ERK signaling pathway. However, further studies are required to elucidate the detailed molecular mechanism of its activity in tumor cell biology, as well as its potential as a therapeutic target in patients with RCC and BM.

\section{Acknowledgements}

Not applicable.

\section{Funding}

The present study was supported by the Beijing Jishuitan Hospital Nova Program (grant no. XKXX201616).

\section{Availability of data and materials}

The datasets used and/or analyzed during the current study are available from the corresponding author on reasonable request.

\section{Authors' contributions}

JPZ and LBM designed the study. ZHL and HDW performed the experiments. JPZ, ZHL and GLH analyzed the data and interpreted the results. HDW prepared the figures. JPZ drafted the manuscript. ZHL and LBM aided in the revisions of the manuscript. JPZ and LBM confirmed the authenticity of all the raw data. All authors have read and approved the final manuscript.

\section{Ethics approval and consent to participate}

The present study was approved by the Ethics Committee of Beijing Jishuitan Hospital (approval no. 201616).

\section{Patient consent for publication}

Not applicable.

\section{Competing interests}

The authors declare that they have no competing interests.

\section{References}

1. Capitanio U, Bensalah K, Bex A, Boorjian SA, Bray F, Coleman J, Gore JL, Sun M, Wood C and Russo P: Epidemiology of renal cell carcinoma. Eur Urol 75: 74-84, 2019.

2. Capitanio U and Montorsi F: Renal cancer. Lancet 387: 894-906, 2016.

3. Zheng T, Zhu C, Bassig BA, Liu S, Buka S, Zhang X, Truong A, Oh J, Fulton J, Dai M, et al: The long-term rapid increase in incidence of adenocarcinoma of the kidney in the USA, especially among younger ages. Int J Epidemiol 48: 1886-1896, 2019.

4. Znaor A, Lortet-Tieulent J, Laversanne M, Jemal A and Bray F: International variations and trends in renal cell carcinoma incidence and mortality. Eur Urol 67: 519-530, 2015.

5. Guida A, Escudier B and Albiges L: Treating patients with renal cell carcinoma and bone metastases. Expert Rev Anticancer Ther 18: 1135-1143, 2018.

6. Molina AMD: A multidisciplinary approach for the management of earlier stage renal cell carcinoma. Urol Oncol 36: 15-16, 2018.

7. Ravaud A, Motzer RJ, Pandha HS, George DJ, Pantuck AJ, Patel A, Chang YH, Escudier B, Donskov F, Magheli A, et al: Adjuvant sunitinib in high-risk renal-cell carcinoma after nephrectomy. N Engl J Med 375: 2246-2254, 2016.

8. Bianchi M, Sun M, Jeldres C, Shariat SF, Trinh QD, Briganti A, Tian Z, Schmitges J, Graefen M, Perrotte P, et al: Distribution of metastatic sites in renal cell carcinoma: A population-based analysis. Ann Oncoly 23: 973-980, 2012.

9. Bosse D, Lin X, Simantov R, Lalani AA, Derweesh I, Chang SL, Choueiri TK and McKay RR: Response of primary renal cell carcinoma to systemic therapy. Eur Urol 76: 852-860, 2019.

10. Joshi SS, Handorf EA, Zibelman M, Plimack ER, Uzzo RG, Kutikov A, Smaldone MC and Geynisman DM: Treatment facility volume and survival in patients with metastatic renal cell carcinoma: A registry-based analysis. Eur Urol 74: 387-393, 2018.

11. Zhuo $\mathrm{H}$ and Zhou L: Gpnmb/osteoactivin: An indicator and therapeutic target in tumor and nontumorous lesions. Pharmazie 71: 555-561, 2016.

12. Rose AAN, Biondini M, Curiel R and Siegel PM: Targeting GPNMB with glembatumumab vedotin: Current developments and future opportunities for the treatment of cancer. Pharmacol Ther 179: 127-141, 2017.

13. Truong DD, Kratz A, Park JG, Barrientos ES, Saini H, Nguyen T, Pockaj B, Mouneimne G, LaBaer J and Nikkhah M: A Human organotypic microfluidic tumor model permits investigation of the interplay between patient-derived fibroblasts and breast cancer cells. Cancer Res 79: 3139-3151, 2019.

14. Baba M, Furuya M, Motoshima T, Lang M, Funasaki S, Ma W, Sun HW, Hasumi H, Huang Y, Kato I, et al: TFE3 Xp11.2 translocation renal cell carcinoma mouse model reveals novel therapeutic targets and identifies GPNMB as a diagnostic marker for human disease. Mol Cancer Res 17: 1613-1626, 2019. 
15. Sondag GR, Mbimba TS, Moussa FM, Novak K, Yu B, Jaber FA, Abdelmagid SM, Geldenhuys WJ and Safadi FF: Osteoactivin inhibition of osteoclastogenesis is mediated through CD44-ERK signaling. Exp Mol Med 48: e257, 2016.

16. Ono Y, Chiba S, Yano H, Nakayama N, Saio M, Tsuruma K, Shimazawa M, Iwama T and Hara H: Glycoprotein nonmetastatic melanoma protein B (GPNMB) promotes the progression of brain glioblastoma via $\mathrm{Na}(+) / \mathrm{K}(+)$-ATPase. Biochem Biophys Res Commun 481: 7-12, 2016.

17. Tian F, Liu C, Wu Q, Qu K, Wang R, Wei J, Meng F, Liu S and Chang $\mathrm{H}$ : Upregulation of glycoprotein nonmetastatic B by colony-stimulating factor- 1 and epithelial cell adhesion molecule in hepatocellular carcinoma cells. Oncol Res 20: 341-350, 2013.

18. Tomihari M, Chung JS, Akiyoshi H, Cruz PD Jr and Ariizumi K: DC-HIL/glycoprotein Nmb promotes growth of melanoma in mice by inhibiting the activation of tumor-reactive $\mathrm{T}$ cells. Cancer Res 70: 5778-5787, 2010.

19. Jin R, Jin YY, Tang YL, Yang HJ, Zhou XQ and Lei Z: GPNMB silencing suppresses the proliferation and metastasis of osteosarcoma cells by blocking the PI3K/Akt/mTOR signaling pathway. Oncol Rep 39: 3034-3040, 2018.

20. Fiorentini C, Bodei S, Bedussi F, Fragni M, Bonini SA, Simeone C, Zani D, Berruti A, Missale C, Memo M, et al: GPNMB/OA protein increases the invasiveness of human metastatic prostate cancer cell lines DU145 and PC3 through MMP-2 and MMP-9 activity. Exp Cell Res 323: 100-111, 2014.

21. Nannuru KC, Futakuchi M, Varney ML, Vincent TM, Marcusson EG and Singh RK: Matrix metalloproteinase (MMP)-13 regulates mammary tumor-induced osteolysis by activating MMP9 and transforming growth factor- $\beta$ Signaling at the tumor-bone interface. Cancer Res 70: 3494-3504, 2010

22. Jianpo Z, Ning L, Hai W, Haidong W and Libo M: Expression of GPNMB, ERK, MMP3 and MMP9 in primary lesion and bone metastasis of renal cell carcinoma and their correlation. Cancer Res Prev Treat 47: 367-371, 2020.

23. Mayo JC, Hevia D, Quiros-Gonzalez I, Rodriguez-Garcia A Gonzalez-Menendez P, Cepas V, Gonzalez-Pola I and Sainz RM: IGFBP3 and MAPK/ERK signaling mediates melatonin-induced antitumor activity in prostate cancer. J Pineal Res: Oct 13, 2016 (Epub ahead of print). doi: 10.1111/jpi.12373.

24. Qin C, Liu Z, Yuan Y, Zhang X, Li H, Zhang C, Xu T and Wang X: Glycoprotein non-metastatic melanoma protein B as a predictive prognostic factor in clear-cell renal cell carcinoma following radical nephrectomy. Mol Med Rep 9: 851-886, 2014.

25. Rose AA, Pepin F, Russo C, Abou Khalil JE, Hallett M and Siegel PM: Osteoactivin promotes breast cancer metastasis to bone. Mol Cancer Res 5: 1001-1114, 2007.

26. Rose AA and Siegel PM: Emerging therapeutic targets in breast cancer bone metastasis. Future Oncol 6: 55-74, 2010.

27. Ramani V, Teshima T, Tamura K, Chung JS, Kobayashi M, Cruz PD Jr and Ariizumi K: Melanoma-derived soluble DC-HIL/GPNMB promotes metastasis by excluding T-Lymphocytes from the pre-metastatic niches. J Nvest Dermatol 138: 2443-2451, 2018.

28. Rose AA, Grosset AA, Dong Z, Russo C, Macdonald PA, Bertos NR, St-Pierre Y, Simantov R, Hallett M, Park M, et al: Glycoprotein nonmetastatic B is an independent prognostic indicator of recurrence and a novel therapeutic target in breast cancer. Clin Cancer Res 16: 2147-2156, 2010.
29. Li YN, Zhang L, Li XL, Cui DJ, Zheng HD, Yang SY and Yang WL: Glycoprotein nonmetastatic B as a prognostic indicator in small cell lung cancer. APMIS 122: 140-146, 2014

30. Ma RQ, Tang ZJ, Ye X, Cheng HY, Sun KK, Chang XH and Cui H: Overexpression of GPNMB predicts an unfavorable outcome of epithelial ovarian cancer. Arch Gynecol Obstet 297: $1235-1244,2018$

31. Arosarena OA, Barr EW, Thorpe R, Yankey H, Tarr JT and Safadi FF: Osteoactivin regulates head and neck squamous cell carcinoma invasion by modulating matrix metalloproteases. J Cell Physiol 233: 409-421, 2018.

32. Bhattacharyya S, Feferman L, Sharma G and Tobacman JK: Increased GPNMB, phospho-ERK1/2, and MMP-9 in cystic fibrosis in association with reduced arylsulfatase B. Mol Genet Metab 124: 168-175, 2018

33. Okita Y, Kimura M, Xie R, Chen C, Shen LT, Kojima Y, Suzuki H, Muratani M, Saitoh M, Semba K, et al: The transcription factor MAFK induces EMT and malignant progression of triple-negative breast cancer cells through its target GPNMB. Sci Signal 10: eak9397, 2017.

34. Chen C, Okita Y, Watanabe Y, Abe F, Fikry MA, Ichikawa Y, Suzuki H, Shibuya A and Kato M: Glycoprotein nmb is exposed on the surface of dormant breast cancer cells and induces stem cell-like properties. Cancer Res 78: 6424-6435, 2018.

35. Kopp LM, Malempati S, Krailo M, Gao Y, Buxton A, Weigel BJ, Hawthorne T, Crowley E, Moscow JA, Reid JM, et al: Phase II trial of the glycoprotein non-metastatic B-targeted antibody-drug conjugate, glembatumumab vedotin (CDX-011), in recurrent osteosarcoma AOST1521: A report from the Children's Oncology Group. Eur J Cancer 121: 177-183, 2019.

36. Tray N, Adams S and Esteva FJ: Antibody-drug conjugates in triple negative breast cancer. Future Oncol 14: 2651-2661, 2018.

37. Ott PA, Hamid O, Pavlick AC, Kluger H, Kim KB, Boasberg PD, Simantov R, Crowley E, Green JA, Hawthorne T, et al: Phase I/II study of the antibody-drug conjugate glembatumumab vedotin in patients with advanced melanoma. J Clin Oncol 32: 3659-3666, 2014.

38. Ott PA, Pavlick AC, Johnson DB, Hart LL, Infante JR, Luke JJ, Lutzky J, Rothschild NE, Spitler LE, Cowey CL, et al: A phase 2 study of glembatumumab vedotin, an antibody-drug conjugate targeting glycoprotein NMB, in patients with advanced melanoma. Cancer 125: 1113-1123, 2019.

39. Rose AA, Annis MG, Frederick DT, Biondini M, Dong Z, Kwong L, Chin L, Keler T, Hawthorne T, Watson IR, et al: MAPK pathway inhibitors sensitize BRAF-mutant melanoma to an antibody-drug conjugate targeting GPNMB. Clin Cancer Res 22: 6088-6098, 2016.

40. Yardley DA, Weaver R, Melisko ME, Saleh MN, Arena FP, Forero A, Cigler T, Stopeck A, Citrin D, Oliff I, et al: EMERGE: A randomized phase II study of the antibody-drug conjugate glembatumumab vedotin in advanced glycoprotein NMB-expressing breast cancer. J Clin Oncol 33: 1609-1619, 2015.

41. Bendell J, Saleh M, Rose AA, Siegel PM, Hart L, Sirpal S, Jones S, Green J, Crowley E, Simantov R, et al: Phase I/II study of the antibody-drug conjugate glembatumumab vedotin in patients with locally advanced or metastatic breast cancer. J Clin Oncol 32: 3619-3625, 2014. 